Article

\title{
Leveraging Employer Practices in Global Regulatory Frameworks to Improve Employment Outcomes for People with Disabilities
}

\author{
Matthew C. Saleh and Susanne M. Bruyère * \\ K. Lisa Yang and Hock E. Tan Institute on Employment and Disability, ILR School, Cornell University, Ithaca, New York, \\ NY 19853, USA; E-Mails: mcs378@cornell.edu (M.C.S.), smb23@cornell.edu (S.M.B.) \\ * Corresponding author
}

Submitted: 30 September 2017 | Accepted: 20 December 2017 | Published: 26 March 2018

\begin{abstract}
Work is an important part of life, providing both economic security and a forum to contribute one's talents and skills to society, thereby anchoring the individual in a social role. However, access to work is not equally available to people with disabilities globally. Regulatory environments that prohibit discrimination and support vocational training and educational opportunities constitute a critical first step toward economic independence. However, they have not proven sufficient in themselves. In this article, we aim to infuse deeper consideration of employer practice and demand-side policy reforms into global policy discussions of the right to work for people with disabilities. We begin by documenting the employment and economic disparities existing for people with disabilities globally, followed by a description of the international, regional, and local regulatory contexts aiming to improve labor market outcomes for people with disabilities. Next, we examine how policies can leverage employer interests to further address inequalities. We discuss employer policies and practices demonstrated in the research to facilitate recruitment, hiring, career development, retention, and meaningful workplace inclusion. The goal of the article is to synthesize existing international literature on employment rights for people with disabilities with the employer perspective.
\end{abstract}

\section{Keywords}

disability; disabled worker; employment; employment equity; employer practices; human resources; international disability policy

Issue

This article is part of the issue "Disability Equality: In Theory and Practice", edited by Mark Priestley (University of Leeds, UK) and Lisa Waddington (Maastricht University, The Netherlands).

(C) 2018 by the authors; licensee Cogitatio (Lisbon, Portugal). This article is licensed under a Creative Commons Attribution 4.0 International License (CC BY).

\section{Introduction}

Work is an important part of life. It is a source of not only economic power, but also social and personal wellbeing. At the most basic level, work provides security by enabling the procurement of food, shelter, and other basic needs for survival and good health. Beyond that, work allows individuals to contribute to the community with their abilities and skills, and provides the means for establishing a social position from which others perceive them. Our jobs often determine how society views us, and therefore influence how we view ourselves. Equi- table access to work is a basic right, and at the core of what it means to be human.

However, individuals with disabilities around the world have not been able to gain equitable access to employment. Many factors contribute to the employment disparities for individuals with disabilities. Among them are unequal preparation for the labor market, insufficient support in finding and retaining employment, and poor awareness among employers about effective recruitment and retention strategies for workers with disabilities. These barriers exist in low-, middle-, and high-income countries alike. Individuals who experience 
a "precarious relationship with the labor market" face additional barriers related to access to social and political participation, as well as necessities integral to quality of life (Harris, Owen, \& Gould, 2012, p. 824). While many people with disabilities are able to achieve gainful employment and societal integration, as a group they face disproportionate poverty and unemployment (International Labour Organization [ILO], 2007a).

The emphasis of this article is on the role that employers - the demand-side of the disability employment continuum - play in improving outcomes for individuals with disabilities, and how government policy initiatives can drive more substantial demand-side effort (Bruyère, 2016). Traditionally, scholars have studied disability employment inequalities from the viewpoint of the individual, particularly focusing on the medical, educational, psychological, and vocational factors that affect a person's work-related functioning and job skills (Chan, Strauser, Gervey, \& Lee, 2010). On the other hand, scholars describe individual rights primarily in relation to governmental action and enforcement. Both approaches tend to overlook "the fact that labor market outcomes such as employment are determined when the supply of individuals' labor aligns with demand for labor on the part of employers" (Bruyère, VanLooy, von Schrader, \& Barrington, 2016, p. 5). In other words, they tend to downplay employer considerations. On the other hand, policies accounting for the demand-side aim to cultivate change at the organizational level in order to improve labor market conditions (Bruyère et al., 2016).

This article further explores the employer side of the international regulatory context, engaging in a discussion of empirically supported best practices in recruitment, hiring, advancement, retention, and full inclusion of individuals with disabilities in the workforce. We set this information in the context of the international legislative and regulatory environment that influences the behavior of employers. Policy approaches that combine supply- and demand-side reforms have not seen proper attention in the global literature, especially as applied to the responsibilities of states parties to the United Nations Convention on the Rights of Persons with Disabilities (UNCRPD). In attempting to bring employer needs to the fore, we advocate policymaking efforts aimed at broadening the pool of stakeholders participating in inclusive hiring practices and increasing the accessibility of the open labor market. Employers who are open to inclusive practices, aware of both the intangible and bottomline benefits of such practices, and equipped with the strategies to implement them, have a powerful role to play in making the labor market favorable to people with disabilities.

\section{Global Situation of Work and Economic Disparities for People with Disabilities}

Individuals with disabilities make up approximately $15 \%$ of the world population, or more than one billion people
(World Health Organization [WHO], 2011). Projections indicate that the number and proportion of people with disabilities worldwide will continue to increase due to aging, chronic health conditions, workplace related incidents, and other factors (Harper, 2013; Houtrow, Larson, Olson, Newacheck, \& Halfon, 2014; Vos et al., 2015). Lowand middle-income countries, often referred to as "developing" nations, have higher rates of disability prevalence than high-income countries: globally, nearly $80 \%$ of people with disabilities reside in low-income nations (WHO, 2011). Despite the high overall demographic representation, people with disabilities continue to be significantly under-represented in the world's labor force.

The employment rate of people with disabilities globally is $44 \%$, compared with $75 \%$ for people without disabilities (WHO, 2011). The inactivity rate for people with disabilities is almost 2.5 times higher: $49 \%$ vs. $20 \%$ (WHO, 2011). Estimates indicate that the social exclusion of people with disabilities from the workplace results in trillions of dollars in annual loss in GDP (Metts, 2000; Ozawa \& Yeo, 2006). In addition to lost labor, the marginalization of people with disabilities in employment creates "structural and social costs," including "high benefit levels and health and social inequalities" (Sainsbury \& ColemanFountain, 2014, p. 2). Lost labor and increased social cost only further magnifies the case for demand-side focus: in many cases, employers are not even aware that they are limiting their talent pools and sacrificing productivity by forgoing inclusive recruitment and hiring practices (Kaye, Jans, \& Jones, 2011). As such, employer practices research indicates that "the competition that drives business innovation could also play a part in encouraging businesses to compete with each other on issues related to diversity and inclusion" (Henry, Petkauskos, Stanislawzyk, \& Vogt, 2014, p. 246).

Disparities exist in nations across economic and political conditions. In 2015, approximately $35 \%$ of working age people with disabilities in the United States attained employment in the open labor market, compared with $78 \%$ of people without disabilities (Erickson, Lee, \& von Schrader, 2017). Similar trends exist in Organization for Economic Cooperation and Development (OECD) countries, where most recent figures estimate the average employment rate for people with disabilities at just over $40 \%$, compared with approximately $75 \%$ for people without disabilities (OECD, 2009). Statistics for OECD nations show that people with disabilities are less likely to have full-time work, more likely to be un- or under-employed, have lower relative income levels, tend to earn less even when employed, and have a higher likelihood of living in poverty (OECD 2009; WHO, 2011). Income levels are much higher among groups of people with disabilities who have high educational attainment or full-time employment (OECD, 2009). Analyses of economic inactivity in the European Union (EU) shows high variation by type and severity of disability (e.g., 75\% unemployment for people with mental illness in the United Kingdom) (ILO, 2007b). 
Surprisingly familiar thematic barriers emerge in many disparate national contexts. These include tensions arising between employees with disabilities and employers due to legislative efforts, immoderate belief in the perceived fairness of open labor market practices, and reliance on stereotypes about people with disabilities' lack of productivity or the expense of accommodating (Harpur \& Bales, 2010). Many of these themes pertain to employer perceptions and resulting practices. In many global contexts, the imposition of duties on employers meet with resistance for these reasons. However, employers who do provide accommodations report that they are typically inexpensive (Dixon, Kruse, \& Van Horn, 2003), have high return-on-investment (Unger, Wehman, Yasuda, Campbell, \& Green, 2002), and result in improved retention rates, organizational culture, and productivity (Kaye, Jans, \& Jones, 2011).

Empirical evidence demonstrates employment disparities in a number of low- and middle-income contexts as well (see, e.g., Hoogeveen, 2005 [Uganda], Lamichhane \& Okubo, 2014 [Nepal], Mitra \& Sambamoorthi, 2008 [India], Mizunoya, Yamasaki, \& Mitra, 2016 [Vietnam], Trani \& Loeb, 2010 [Afghanistan, Zambia]). Mizunoya and Mitra (2013) assessed the employment gaps in fifteen low- and middle-income countries in Africa, Asia, and Latin America, and found statistically significant employment gaps for people with disabilities in nine out of the fifteen examples; interestingly, the six countries that had either no gap or a statistically insignificant gap were low-income nations, while all but two with a significant employment gap were middle-income.

Where poverty is widespread, persistent disability is often an additional dimension to poverty, rather than the fundamental cause (Eide \& Ingstad, 2011). For this reason, Yeo and Moore (2003) describe the social, cultural, and political processes that link disability and poverty as a "vicious circle." The dimensions of the link between disability and poverty differ significantly between lowand high-income contexts, and causality can run in either direction - that is, poverty can also lead to disability. We can see this in the examples of lack of workplace safety regulations, inadequate healthcare interventions, poor nutrition and hygienic conditions, pollution, and higher prevalence of inaccessible or disabling environments. Lower income levels may also affect people with disabilities differently: additional costs for personal support, medical care, and/or assistive devices can result in greater odds of experiencing financial hardship than peers without disability at similar income levels (e.g., catastrophic health expenditure) (WHO, 2011). Government spending and activity in poverty alleviation for households that have an individual with a disability also lead to unexpected interactions. In countries where poverty is endemic, the introduction of disability grants or pensions can lead to markedly improved standards of living (Loeb, Eide, Jelsma, Ka'Toni, \& Maart, 2007). However, in high-income countries, scholars cite such benefits as potential "poverty traps" that "contribute to ex- clusion from the labor market and result in a comparably low life income" (Eide \& Ingstad, 2011, p. 5).

Issues of access to social institutions constitute one of the most intractable barriers to employment and quality of life. Access to education and training provides pathways to employment, whereas marginalization in educational opportunities only furthers employment disparities. In particular, youth with disabilities constitute a "significant proportion of the youth population in every society," and estimates indicate that approximately $80 \%$ of youth with disabilities (ages 15 to 24), or between 180 and 220 million people, live in developing countries (U.N. Division of Social Policy and Development [DSPD], 2010 , p. 2). Yet youth with disabilities are less likely to start school in the first place, have lower rates of enrollment and promotion in school, and lower transition rates to post-secondary education and work than their peers without disabilities (WHO, 2011). Many countries exclude people with disabilities from mainstream schooling, and have inadequate or fragmentary school-to-work transition frameworks (Stewart, 2009).

The overall lack of services and coordination often leads to a "difficult period of upheaval and uncertainty" as youth with disabilities "transition from childhood into adulthood, primarily in the area of achieving successful employment and independent living" (DSPD, 2010, p. 4). For instance, analysis from four southern African nations found difficulties accessing rehabilitation services (between $26 \%-55 \%$ obtained needed services) and vocational training (between 5\%-23\%) (WHO, 2011). Even in high-income nations with comparatively robust rehabilitation and social service offerings, people with disabilities often report not having their everyday service needs met (between 20\%-40\%) (WHO, 2011). At the intersection of supply and demand, lies the availability of skilled workers equipped to meet the needs of the market. As policy concerns, the expansion of educational opportunities, demand-driven skills training, rehabilitation services, and career development opportunities for people with disabilities are of paramount importance (ILO, 2010).

\subsection{International Framework for Employment and Training}

The UNCRPD was the first binding international human rights treaty to codify the rights of people with disabilities on a global scale. Adopted by the General Assembly in December of 2006, the UNCRPD currently has 160 signatories and 174 ratifying parties (U.N. Enable, 2017). The Convention covers a broad array of human rights topics, including an explicit right to work and related rights pertaining to non-discrimination, awareness raising, education and training, rehabilitation, accessibility, and quality of life. The UNCRPD is a powerful international legal instrument, but as a corrective, its effectiveness is subject to national and local variation. The role of employer practices has been under-explored in schol- 
arship on UNCRPD implementation (see, e.g., Brayley, 2012; Owen \& Harris, 2012; Power, Lord, \& deFranco, 2013). This is not entirely surprising, as human rights instruments generally conceptualize "rights" (often in a negative rights sense), as inhering in the individual, or alternatively seek to impose affirmative responsibilities on stakeholders without adequate attention to converging interests. However, the UNCRPD does contain certain mandates for states parties to facilitate demandside buy-in, such as employer awareness building and incentives, and market-driven skills development practices. These elements of the CRPD warrant deeper discussion.

With any international treaty, ratification makes the terms of the agreement legally binding, although enforcement typically falls within the purview of state parties through processes of domestic incorporation (Lord \& Stein, 2008). As such, "substantive rights will often get their complexion from the local cultural environment within which they have to be given concrete, practical meaning" (Ncube, 1998, pp. 14-15). Moreover, depending on the level of centralization in legal, regulatory, and enforcement mechanisms, regional variations may also shape the prospects of people with disabilities seeking to exercise their rights. For instance, in the area of employment and work, "the number, size and type of companies in the region, compliance to the law among employers, and the resources, skills and competencies of the regional employment services" may all moderate the practical effect of employment policies and laws (Sainsbury \& Coleman-Fountain, 2014, p. 22).

Work and training topics play a prominent role in the UNCRPD. Article 26(1) requires that parties organize, strengthen, and/or extend comprehensive habilitation and rehabilitation programs and services in the areas of health, employment, education and social services, including effective measures "to enable persons with disabilities to attain and maintain maximum independence, full physical, mental, social and vocational ability, and full inclusion and participation in all aspects of life." Article 27 outlines the right to work and employment "on an equal basis with others." This includes the "opportunity to gain a living by work freely chosen or accepted in a labor market and work environment that is open, inclusive and accessible." It also places a prohibition on employer discrimination (hiring, retention, and advancement), and provides rights to equal remuneration, reasonable accommodation, favorable and safe working conditions, systems for redress of grievances, union participation, and access to technical and vocational guidance and training. These are more traditional human rights edicts, primarily guaranteeing the individual a right to equal access and nondiscrimination.

However, Article 27 also calls for parties to promote advancement and return-to-work efforts, as well as alternative pathways to employment such as selfemployment, entrepreneurship, cooperatives, public sector employment, and affirmative action programs/incentives. Article $27(1)(h)$ holds that states parties shall "promote the employment of persons with disabilities in the private sector through appropriate policies and measures, which may include affirmative action programmes, incentives and other measures." 27(1)(j) requires that participants "promote the acquisition...of work experience in the open labour market." Article 24 further contains language implicating not only a nexus between education and the right to work, but also identifying the importance of vocational training, tertiary education, and lifelong learning as human rights. Objectives like this steer the Convention into the territory of demand-side considerations-or at least into the convergence of supply and demand interests-such as employer incentives and market-driven (competitive) skills development. The UNCRPD is a modern human rights instrument, outlining rights consistent with a "substantive" notion of equality. That is, it distinguishes equal treatment from identical treatment, and extends policies beyond negative rights, towards eliminating the conditions that perpetuate discrimination (see, e.g., Committee on Economic, Social and Cultural Rights, 1994).

The balancing of supply- and demand-side policy reforms must also account for local economic factors: for instance, the concept of "productivity" in labor is contingent on which economic sectors predominate in a given region. Lower-income nations tend to feature agrarian economies where the primary sectors (e.g., agriculture, forestry, mining) account for a large share of the jobs, whereas in middle- and high-income countries, the secondary (manufacturing) and tertiary (services) sectors may be more extensive. Policy incentives, injections, and offsets must account for not only existing conditions, but also future trends. Demand-driven reforms can help enhance the agency and participation of private sector stakeholders-especially those less inclined to participate on social grounds. However, reform efforts must not merely cater to employer interests. They must utilize incentives, services, and training opportunities to "restore more choice and control to people with disabilities over the types of support they may need," and prioritize "facilitation mechanisms such as independent planning and supported decision making" (Power et al., 2013, pp. 441-442). Efforts that increase civil society's participation by fomenting employer action are good; efforts that do so while increasing agency and selfdetermination for people with disabilities are better.

\subsection{Approaches to Implementation}

The primary strategy of industrialized welfare states has been an investment in employment readiness and training programs and anti-discrimination legislation (Grover \& Piggott, 2007; Humpage, 2007). However, at the time of the UNCRPD's adoption, there existed substantial heterogeneity in the types of legal protections and service systems available to people with disabilities on a country-by-country basis. The creation of new international norms must be backed by regional, national, 
and local implementation efforts, as the "touchstone of the CRPD's significance is whether it changes policies and practices at national level[s] and whether it makes any difference in the actual living conditions of persons with disabilities" (Waldschmidt, Sturm, Karačić, \& Dins, 2017, p. 177).

Cultural attitudes remain a major threshold obstacle, particularly when it comes to implementing sweeping reforms "in a manner that responds to broad obligations while being duly consonant to domestic social and legal norms" (Lord \& Stein, 2013, p. 99). For instance, analysis by Dinerstein (2017) noted that many Southeast Asian countries implicitly perpetuated medical views of disability by choosing social welfare or health agencies as the implementation "focal point," rather than justice-based agencies. Furthermore, enforcement of non-discrimination provisions can be expensive and beyond the means of countries that lack an existing mechanism. For example, one analysis found that most Pacific Island states lacked appropriately comprehensive frameworks for enforcement (Harpur \& Bales, 2010). While it is outside the scope of this article to provide a comprehensive review of disability policy worldwide, in this section we provide some instructive examples of the various contextual issues at national and regional levels, particularly those that touch upon employer practices, interest convergence, and policies that encourage (rather than merely compelling) employer action.

Innovations in policies encouraging supported employment can play a role in bridging employee and employer needs. Certain EU countries (e.g., Germany, Sweden, and Norway) have developed programs to afford supported employment opportunities to people with disabilities (Waldschmidt et al., 2017). In Germany, this includes training and support in work, protecting the right to employment for people with severe disabilities, and legally defined special allowances in the workplace (tax relief, a parking badge, and protection against dismissal) (Sainsbury \& Coleman-Fountain, 2014). Germany's social services subsystem offers vocational training centers for youth with disabilities, re-training centers for adults, and integration centers that help individuals with severe disabilities identify and maintain employment, move from training centers to work, and liaise with employers to moderate accommodations and special dismissal procedures. In Sweden, supported employment entails financial support for the purchase of assistive devices in the workplace by employers or individuals, as well as "special introduction and follow-up support" services (before or during the introductory period of a job and up to a year after employment commences) (Committee on the Rights of Persons with Disabilities, 2012). Norway promotes supported employment through subsidies, grants, assistive technology centers, vocational training and higher education opportunities, and incentives for the provision of accommodations (Sainsbury \& Coleman-Fountain, 2014). Overall, the emphasis appears to have been effective: from 2000-2010, a 50\% increase occurred in the population of Norwegians with disabilities working in supported employment (Official Norwegian Reports, 2012).

Italy instituted measures for a targeted employment framework, graduated hiring quota, and regionally implemented assessment guidelines for work capacity, job-matching candidate's skill set to employer needs, and training criteria (Agovino \& Rapposelli, 2011; Law $68 / 1999$ ). Penalties exist for failing to meet quotas (companies of 15-35 employees must hire one individual, 36-50 must hire two, and 50 or more have a quota of $7 \%$ ), while conversely employers may receive incentives for employing people with disabilities, such as tax subsidies, wage contributions, and reimbursement for workplace adaptations (Sainsbury \& Coleman-Fountain, 2014). Quota systems have been a popular policy directive in a number of contexts, with some nations opting to penalize, others to incentivize, and still others to treat quotas as explicitly or implicitly (due to lack of enforcement mechanism) aspirational. On the incentives side, Uganda, for instance, has provided tax cuts for private sector employers who employ people with disabilities at a rate of $5 \%$ of their total workforce (The Persons with Disability Act, 2006). However, 2009 amendments cut the available tax refund from $15 \%$ to $2 \%$ (Income Tax Amendment Act, 2009), a figure that commentators note is unlikely to provide the needed incentive to employers (Nyombi \& Kibandama, 2014).

In some contexts, there is an element of choice. The Czech system, for instance, allows employers to employ people with disabilities "directly," or "indirectly" by commissioning goods and services from organizations that do: for 2010, direct employment accounted for $56 \%$ of the obligations met (Committee on the Rights of Persons with Disabilities, 2013; see also The Employment Act, 2004). Governments often allow employers to miss the quota in exchange for payment of a penalty or additional taxation. Serbia's quota system outlines penalties and subsidies for missing, making, or exceeding targets (see Act on Professional Rehabilitation and Employment of Persons with Disabilities, 2009; Prohibition of Discrimination Act, 2009). While many employers choose to pay the fine rather than comply, the government applies penalties to employment, education, and poverty reduction initiatives for people with disabilities (Sainsbury \& Coleman-Fountain, 2014).

In many European states, Active Labour Market Policies (ALMPs) aim to improve the functioning of the labor market by directing policies towards unemployed persons, including targeted populations vulnerable to labor market exclusion (Waddington, Pedersen, \& Ventegodt Liisberg, 2016). In this way, ALMPs direct policy efforts towards both the supply and demand-side of laborequipping unemployed individuals with demand-driven skills needed to enter the labor market while simultaneously offering incentives to employers (Auer, Berg, \& Cazes, 2007). The Council of Europe formalized a preference for ALMPs in its 2015 Guidelines for Member State 
employment policies (Council of Europe, 2015). Commentators note that these policies are not without downsides, as many national efforts have led them to adopt "work-first" measures that place pressure on individuals to leave or phase out of benefits programs. This can result in the deterioration of financial position and security for individuals who struggle to find adequate employment (Waddington et al., 2016).

Denmark has become an interesting case for ALMP reforms, both because of its high rates of general employment and "flexicurity" labor market model (Ventegodt Liisberg, 2011). The flexicurity model prioritizes both high levels of income support during unemployment and quick reentry into the labor force, especially through upgrading of skills and "activation" obligations for unemployed individuals (Danish Government, 2013). The percentage of Danish individuals with disabilities in supported employment conditions rose from less than $10 \%$ in 2002 to more than 25\% in 2014 (Waddington et al., 2016). The Danish policy framework focuses on incentivizing, rather than merely compelling employers (e.g., no quota, high degree of freedom in termination/hiring decisions). Denmark's system includes subsidies for "ice breaker" wages for recent graduates, flexjobs (subsidized wages for transitional work in special working conditions such as adapted environments or schedules), workplace alterations, mentor opportunities, job trials, and technical or personal assistance (Gupta, Larsen, \& Thomsen, 2015).

Thus far we have provided background and examples of the global, regional, and local regulatory efforts to minimize employment discrimination and maximize employment outcomes, including by formulating policies which account for employer needs and interests as stakeholders (with varying levels of duty and responsibility for private sector employers). Against this backdrop, we turn now to the subject of employer practices, and adaptations to workplace culture that can support an inclusive, 21st century workforce amenable to hiring people with disabilities while also keeping the business case in focus.

\section{The Importance of Employer Practices}

Regulatory environments often aim not only to improve job-seeker prospects (through education, vocational training, VR services, etc.), but also to positively affect employer behavior (through incentives, nondiscrimination rules, awareness raising, etc.). Therefore, the critical next step in our examination of meaningful labor market inclusion draws us closer to the actual employment experience, and to the functioning of the enterprise itself. In this section, we discuss common organizational weaknesses and promising employer practices to help frame the strategies that governments may bake into their policy directives. Research indicates that private employers who value workforce diversity desire additional government support in adapting their recruitment and hiring practices-perhaps even beyond legally prescribed levels-and are more open to collaborating with government agencies who "understand their needs" (Henry et al., 2014).

Employers around the globe are beginning to acknowledge that people with disabilities make reliable and productive employees, and that "having a diverse workforce inclusive of those with a disability makes for a sound business case" (Kulkarni \& Gopakumar, 2014, p. 446). The business case for diverse hiring practices, grounded in substantial research, operates under two notions. First, that when provided with an enabling environment, people with disabilities represent a qualified but under-tapped pool of potential workers (direct productivity). Second, that people with disabilities contribute to a diverse workforce, with attendant benefits for workplace culture, morale, and organizational reputation (indirect productivity) (ILO, 2010). Research into organizational diversity actually goes even further, indicating collateral benefits such as lower costs of discrimination and liability, greater organizational problem solving capacity, more innovation, and stronger appeal to a diverse customer base (Yap \& Konrad, 2009).

Setting policy aside, the critical initial step in getting people with disabilities into the workplace lies with the employer's recruitment, selection, and hiring processes, which may take different forms in different regions and economies. Throughout the discussion of employer practices, we encourage consideration of how government policy can reify abstract notions of equality in the workplace (turn policy into practice). Companies respond differently to public policy directives in the area of disability employment: research from Norway and Sweden, for instance, indicates certain prevalent themes in large companies' approaches to recruitment, including the importance of support beyond mere financial incentives or offsets (e.g., advisory support or technical assistance) and the importance of "value choices" by management (Kuznetsova \& Yalcin, 2017). Studies further show that employer knowledge, especially at HR and management levels, is a key threshold ingredient affecting employer commitment to disability inclusive hiring, including training of management in pertinent legal requirements and potential workplace accommodations (Chan, Strauser, Maher, et al., 2010). Government-sponsored incentives, awareness raising, and technical assistance efforts help alert management personnel of recruitment strategies, while national and local employment services can play a key role in connecting employers to job seekers with disabilities (Luecking, 2011). Research from the United Kingdom highlights the benefits of flexible, personalized approaches to job placement, which offer supported employment opportunities through careful job matching, on-the-job support, and barrier reduction (Roulstone, Harrington, \& Hwang, 2014).

In a study conducted in the U.S., researchers asked 700 human resource (HR) professionals whether their organizations had put in place any of ten policies and practices that facilitate recruitment and hiring of individuals with disabilities (Erickson, von Schrader, Bruyère, Van- 
Looy, \& Matteson, 2014). More than half reported including disability in their diversity and inclusion statements (59\%), requiring sub-contractors/suppliers to adhere to disability nondiscrimination requirements (57\%), and having relationships with community organizations that promote the hiring of people with disabilities (54\%). Far fewer reported having explicit organizational goals related to the recruitment and hiring of people with disabilities (25\%), or participating in internships or similar programs that target people with disabilities (19\%). $45 \%$ reported that their companies actively recruit individuals with disabilities, and $38 \%$ reported having senior management that demonstrates a strong commitment to hiring people with disabilities. Evidence suggests that only a small share of employers actively recruit workers with disabilities (Domzal, Houtenville, \& Sharma, 2008). However, further analysis demonstrates that the more of these practices a company reports, the more likely they are to hire people with disabilities. Those organizations reporting targeted internship programs were almost six times as likely to have hired a person with a disability in the past year; those with strong senior management commitment were almost five times as likely; and those reporting relationships with a community organization were almost three times as likely (Erickson et al., 2014).

Certain multinational corporations have recently taken it upon themselves to become leaders in recruitment efforts, in part as a means to broadening their available talent pools as well as viewing "neurodiversity as a competitive advantage" (Austin \& Pisano, 2017, p. 96). For example, German-based software company SAP developed a goal of $1 \%$ of its workforce to be individuals with autism by 2020 through extensive recruitment, screening, and training initiatives (Shumaker, 2015). In recent years, a number of multinational companies have reformed their HR practices as a means to accessing neurodiverse talent. These include Hewlett Packard Enterprise (now DXC Technologies), Microsoft, Willis Towers Watson, Ford, and Ernst \& Young; others like Caterpillar, Dell Technologies, Deloitte, IBM, JPMorgan Chase, and UBS, have pilot or exploratory efforts in motion (Austin \& Pisano, 2017). In addition to finding promising examples among large employers, public sector employment practices are often fundamental to driving reform in hiring practices. This is why advocates often push governments to conduct themselves as model employers (Brooks, Doughtery, \& Price, 2015). Research suggests that private employers often look to the public sector for support in adapting their recruitment and hiring practices (Henry et al., 2014).

Getting into the workplace is only the first hurdle in employment for individuals with disabilities. Once an individual acquires a position, career development and advancement also pose challenges, and are often the site of employment discrimination against people with disabilities. People with disabilities report perceived bias in the career advancement process within organizations (von Schrader \& Nazarov, 2016), are paid less and hold less-desirable jobs than their non-disabled peers (Kruse \& Schur, 2003), and are far less likely to work in management, professional, and related occupations than their peers without disabilities (31.3\% compared with $39.2 \%$ ) (U.S. Bureau of Labor Statistics, 2016). People with disabilities also tend to experience jobs with less autonomy and decision-making compared to their peers without disabilities, as well as jobs that require less education (Colella \& Bruyère, 2011). This may result from the absence of proper procedures for handling retention and advancement issues - in the US context, for instance, few employers report offering mentoring $(17 \%)$ or career planning and development tools (16\%), and even fewer have explicit goals or standards for retaining and advancing employees with disabilities (Erickson, von Schrader, Bruyère, \& VanLooy, 2013).

More commonly, U.S. companies have formal policies for return to work or disability management (76\%), and for flexible work arrangements (57\%) (Erickson et al., 2013). Disability management mitigates the impact of the disability by offering comprehensive services, accommodations and workplace modifications (Doyle, Dixon, \& Moore, 2003). Common practices include personalized case management, stay-at-work and transitional work assignments, creativity in making accommodations, building support systems using community resources, and training managers (Von Schrader, Bruyère, Malzer, \& Erickson, 2013). Flexible work arrangements might include adapting schedules or leave to accommodate medical needs, part-time or seasonal schedules, phased retirement, flex-place arrangements, and more (von Schrader et al., 2013).

Professional development and career development practices are a critical component of inclusive employment policies at the organizational level, and can contribute to employee retention rates (Hausknecht, Rodda, \& Howard, 2009), yet have received inadequate treatment in the employment-focused literature relative to other topics. In a study examining research on employment of people with disabilities research across a 20-year period (1990-2010), articles about workplace accommodation, organizational culture, recruitment and hiring were published with significantly greater frequency than research on retention and advancement (Karpur, VanLooy, \& Bruyère, 2014). For most employers, there remains quite a bit of work to do in improving career advancement and retention practices. Importantly, such practices potentially benefit all employees, both with and without disabilities. Interestingly, personalized approaches to career development are not the norm in corporate settings, despite the fact that "flexible, supportive organizations" benefit all employees' career development (Schur, Kruse, \& Blanck, 2005).

\section{Conclusion}

By framing the discussion starting with broad public policy directives and challenges, then zooming in to nation-level 
strategies for facilitating private sector buy-in and later to actual employer practices, we hope that we have helped to apply a rudimentary taxonomy to the complicated task of converting broad international directives (policies) into real-world changes at the market and organizational levels (practice). Despite heterogeneous political and economic contexts from country-to-country, the leveling of employment opportunities is a persistent public policy challenge (from training to job procurement to advancement and beyond). This is true of low- and middle-income countries with minimal frameworks for legal enforcement or workforce development, as well as high-income countries with substantial mechanisms for both.

While the particular public policy challenges take on a national flavor defined by cultural attitudes, political and economic models, predominant market sectors, and available systems, services, and opportunities for redress, evidence from around the globe demonstrates that antidiscrimination mechanisms and workforce development offerings alone may not be enough to manifest truly inclusive conditions. Newer strains of public policy in the area of disability employment have begun to extend into the realm of employer practices, and the convergence of interests among policymakers, employers, and individual workers or jobseekers. For instance, countries have begun to adopt an array of interventions to try to address education/training inequities to facilitate skill development in an increasingly competitive labor market, as well as supports to facilitate transition to this marketplace for talent in an increasingly technologyintensive business environment.

There is a need for evaluation of these interventions, to identify effective practices that policymakers can replicate in different contexts across low-, middle, and high-income countries. This must occur with reference to the specific context, such as how these interventions play out in the actual hiring, retention, and advancement of individuals with disabilities. The desired outcome of improved employment prospects for people with disabilities globally must be a multi-stakeholder effort, which includes government, education/training, employers, community service providers and the disability advocacy movement. Policies that attempt to widen the net by bringing new stakeholders into the effort of creating inclusive markets as collaborators and beneficiaries offer new pathways to driving effective reform.

\section{Conflict of Interests}

The authors declare no conflict of interests.

\section{References}

Act on Professional Rehabilitation and Employment of Persons with Disabilities of 2009, RS No. 53/95, 3/96, 54/96, 32/97, 64/99, 44/99 and 101/05 (2009). Retrieved from www.legislationline.org/documents/ id/19333
Agovino, M., \& Rapposelli, A. (2011). Inclusion of disabled people in the Italian labour market: An efficiency analysis of law 68/1999 at regional level. Quality \& Quantity, 47(3), 1577-1588.

Auer, P., Berg, J., \& Cazes, S. (2007). Balancing flexibility and security: The role of labour market policies and institutions. Tilburg Law Review, 14(1), 49-56.

Austin, R., \& Pisano, G. (2017). Neurodiversity as a competitive advantage. Harvard Business Review, MayJune, 1-9.

Brayley, J. (2012). The future of supported and substitute decision-making. Paper presented at the World Congress of Adult Guardianship. Melbourne, Australia.

Brooks, D., Doughtery, B., \& Price, J. (2015). The federal government as a model employer and its impact on employment civil rights in America. Employee Rights and Employment Policy Journal, 19(2), 151-188.

Bruyère, S. M. (Ed.). (2016). Disability and employer practices: Research across the disciplines. Ithaca, NY: Cornell University Press.

Bruyère, S. M., VanLooy, S. A., von Schrader, S., \& Barrington, L. (2016). Disability and employment: Framing the problem and our transdisciplinary approach. In S. M. Bruyère (Ed.), Disability and employer practices: Research across the disciplines (pp. 1-26). Ithaca, NY: Cornell University Press.

Chan, F., Strauser, D., Gervey, R., \& Lee, E. J. (2010). Introduction to demand-side factors related to employment of people with disabilities. Journal of Occupational Rehabilitation, 20(4), 407-411. https:// doi.org/10.1007/s10926-010-9243-7

Chan, F., Strauser, D., Maher, P., Lee, E., Jones, R., \& Johnson, E. T. (2010). Demand-side factors related to employment of people with disabilities: A survey of employers in the Midwest region of the United States. Journal of Occupational Rehabilitation, 20(4), 412-419.

Colella, A., \& Bruyère, S. M. (2011). Disability and employment: New directions for industrial/organizational psychology. In American Psychological Association Handbook on Industrial Organizational Psychology (Vol. 1, pp. 473-503). Washington, DC: American Psychological Association.

Committee on Economic, Social and Cultural Rights. (1994). General Comment No. 5, HRI/GEN/1/Rev 8, Add.1.

Committee on the Rights of Persons with Disabilities. (2012). Implementation of the Convention on the Rights of Persons with Disabilities. Initial reports submitted by States parties under article 35 of the Convention: Sweden. CRPD/C/SWE/1.

Committee on the Rights of Persons with Disabilities. (2013). Implementation of the Convention on the Rights of Persons with Disabilities: Initial reports submitted by States parties under article 35 of the Convention: Czech Republic. CRPD/C/CZE/1.

Council of Europe. (2015). Council Decision (EU) 
2015/1848 of 5 October 2015 on guidelines for the employment policies of the Member States for 2015 [2015] OJ L268/28.

Danish Government. (2013). Disability policy action plan 2013: One society for all. Retrieved from http:// www.oim.dk/media/14375/disability-policy-actionplan-2013-one-society-for-all.pdf

Dinerstein, R. (2017). Norm diffusion and CRPD implementation and ASEAN. In D. L. Cogburn \& T. Kempin Reuter (Eds.), Making disability rights real in Southeast Asia: Implementing the UN Convention on the Rights of Persons with Disabilities in ASEAN. Lanham, MD: Lexington Books.

Dixon, K. A., Kruse, D., \& Van Horn, C. E. (2003). Restricted access: A survey of employers about people with disabilities and lowering barriers to work. New Brunswick, NJ: Rutgers University Heldrich Center for Workforce Development.

Domzal, C., Houtenville, A., \& Sharma, R. (2008). Survey of employer perspectives on the employment of people with disabilities: Technical report (Prepared under contract to the Office of Disability and Employment Policy, U.S. Department of Labor). McLean, VA: CESSI.

Doyle, R. H., Dixon, C. G., \& Moore, C. L. (2003). Expanding rehabilitation services to meet the legal needs of aging Americans. Journal of Rehabilitation, 69(2), 49-54.

Eide, A. H., \& Ingstad, B. (2011). Disability and poverty: A global challenge. Bristol, UK: Policy Press.

Erickson, W. A., Lee, C., \& von Schrader, S. (2017). 2015 Disability status report: United States. Retrieved from http://www.disabilitystatistics.org

Erickson, W. A., von Schrader, S., Bruyère, S. M., \& VanLooy, S. A. (2013). The employment environment: Employer perspectives, policies, and practices regarding the employment of persons with disabilities. Rehabilitation Counseling Bulletin, 57(4), 195-208. https://doi.org/10.1177/0034355213509841

Erickson, W. A., von Schrader, S., Bruyère, S. M., VanLooy, S. A., \& Matteson, D. S. (2014). Disability-inclusive employer practices and hiring of individuals with disabilities. Rehabilitation Research, Policy, and Education, 28(4), 309-328. https://doi.org/10.1891/21686653.28.4.309

Grover, C., \& Piggott, L. (2007). Social security, employment and incapacity benefit: Critical reflections on a new deal for welfare. Disability \& Society, 22(7), 733-746.

Gupta, N. D., Larsen, M., \& Thomsen, L. B. (2015). Do wage subsidies for disabled workers reduce their non-employment? Evidence from the Danish Flexjob scheme. IZA Journal of Labor Policy, 4(10), 1-5.

Harper, S. (2013). Ageing societies: Myths, challenges and opportunities. New York: Routledge.

Harpur, P., \& Bales, R. (2010). The positive impact of the Convention on the Rights of Persons with Disabilities: A case study on the South Pacific and lessons from the US experience. Northern Kentucky Law Review, 37(4), 363-388.
Harris, S. P., Owen, R., \& Gould, R. (2012). Parity of participation in liberal welfare states: Human rights, neoliberalism, disability and employment. Disability \& Society, 27(6), 823-836.

Hausknecht, J. P., Rodda, J. M., \& Howard, M. J. (2009). Targeted employee retention: Performance-based and job-related differences in reported reasons for staying. Human Resource Management, 48(2), 269-288. https://doi.org/10.1002/hrm

Henry, A. D., Petkauskos, K., Stanislawzyk, J., \& Vogt, J. (2014). Employer-recommended strategies to increase opportunities for people with disabilities. Journal of Vocational Rehabilitation, 41(3), 237-248.

Hoogeveen, J. (2005). Measuring welfare for small but vulnerable groups: Poverty and disability in Uganda. Journal of African Economies, 14(4), 603-631.

Houtrow, A. J., Larson, K., Olson, L. M., Newacheck, P. W., \& Halfon, N. (2014). Changing trends of childhood disability, 2001-2011. Pediatrics, 134(3), 530-538.

Humpage, L. (2007). Models of disability, work and welfare in Australia. Social Policy and Administration, 41(3), 215-231.

Income Tax Amendment Act of 2009. Act 15. Retrieved from http://www.ulrc.go.ug/system/files_force/ulrc _resources/income-tax-amendment-act-2009.pdf

International Labour Organization. (2007a). Facts on disability in the world of work. Geneva: International Labour Organization.

International Labour Organization. (2007b). The right to decent work of persons with disability. Geneva: International Labour Organization.

International Labour Organization. (2010). Disability in the workplace: Company practices. Geneva: International Labour Organization.

Karpur, A., VanLooy, S. A., \& Bruyère, S. M. (2014). Employer practices for employment of people with disabilities: A literature scoping review. Rehabilitation Research, Policy, and Education, 28(4), 225-241.

Kaye, H. S., Jans, L. H., \& Jones, E. C. (2011). Why don't employers hire and retain workers with disabilities? Journal of Occupational Rehabilitation, 21(4), 526-536.

Kruse, D., \& Schur, L. (2003). Employment of People with Disabilities following the ADA. Industrial Relations, 42(1), 31-66. https://doi.org/10.1111/1468232X.00275

Kulkarni, M., \& Gopakumar, K. V. (2014). Career management strategies for people with disabilities. Human Resource Management, 53(3), 445-466.

Kuznetsova, Y., \& Yalcin, B. (2017). Inclusion of persons with disabilities in mainstream employment: is it really all about the money? A case study of four large companies in Norway and Sweden. Disability \& Society, 32(2), 233-253.

Lamichhane, K., \& Okubo, T. (2014). The nexus between disability, education, and employment: Evidence from Nepal. Oxford Development Studies, 42(3), 439-453. 
Loeb, M., Eide, A. H., Jelsma, J., Ka'Toni, M., \& Maart, S. (2007). Poverty and disability in Eastern and Western Cape Provinces, SA. Disability and Society, 23(4), 311-321.

Lord, J. E., \& Stein, M. A. (2008). The domestic incorporation of human rights law and the United Nations Convention on the Rights of Persons with Disabilities. Washington University Law Review, 83(4), 449-479.

Lord, J., \& Stein, M. A. (2013). Prospects and practices for CRPD implementation in Africa. African Disability Rights Yearbook, 1(1), 97-114.

Luecking, R. G. (2011). Connecting employers with people who have intellectual disability. Intellectual and Developmental Disabilities, 49(4), 261-273.

Metts, R. L. (2000). Disability issues, trends and recommendations for the World Bank. Washington, DC: The World Bank.

Mitra, S., \& Sambamoorthi, U. (2008). Disability and the rural labor market in India: Evidence for males in Tamil Nadu. World Development, 36(5), 934-952.

Mizunoya, S., \& Mitra, S. (2013). Is there a disability gap in employment rates in developing countries? World Development, 42(1), 28-43.

Mizunoya, S., Yamasaki, I., \& Mitra, S. (2016). The disability gap in employment rates in a developing country context: New evidence from Vietnam. Economics Bulletin, 36(2), 771-777.

Ncube, W. (1998). The African cultural footprint? The changing conception of childhood. In W. Ncube (Ed.), Law, culture, tradition and children's rights in Eastern and Southern Africa. Farnham, UK: Ashgate Publishing.

Nyombi, C., \& Kibandama, A. (2014). Access to employment for persons with disabilities in Uganda. Labor Law Journal, 65(4), 248-258.

OECD. (2009). Sickness, disability and work: Keeping on track in the economic downturn. Paper presented at the High-Level Forum, 14-15 May 2009, Stockholm, Sweden. Retrieved from https://www.oecd.org/els/ emp/42699911.pdf

Official Norwegian Reports. (2012). Labour market measures. Oslo: Office of the Prime Minister and Ministries.

Owen, R., \& Harris, S. P. (2012). 'No rights without responsibilities': Disability rights and neoliberal reform under New Labour. Disability Studies Quarterly, 32(3).

Ozawa, M. N., \& Yeo, Y. H. (2006). Work status and work performance of people with disabilities: An empirical study. Journal of Disability Policy Studies, 17(3), 180-190.

Power, A., Lord, J., \& deFranco, A. (2013). Active citizenship and disability: Implementing the personalisation of support. Cambridge: Cambridge University Press.

Prohibition of Discrimination Act of 2009, Official Gazette of the Republic of Serbia No 22/2009 (2009). Retrieved from http://ravnopravnost.gov.rs/ en/legislation/republic-of-serbia-legislation
Roulstone, A., Harrington, B., \& Hwang, S. K. (2014). Flexible and personalised? An evaluation of a UK tailored employment support programme for jobseekers with enduring mental health problems and learning difficulties. Scandinavian Journal of Disability Research, 16(1), 14-28.

Sainsbury, R., \& Coleman-Fountain, E. (2014). Diversity and change of the employment prospects of persons with disabilities: The impact of redistributive and regulatory provisions in a multilevel framework. DISCIT Deliverable 5.1. Retrieved from https://www. researchgate.net/profile/Edmund_Coleman-Fountain /publication/310766875_Diversity_and_Change_of_ the_Employment_Prospects_of_Persons_with_Dis abilities_The_Impact_of_Redistributive_and_Regu latory_Provisions_in_a_Multilevel_Framework/links /5836071408aed45931c649c0/Diversity-and-Change -of-the-Employment-Prospects-of-Persons-with-Dis abilities-The-Impact-of-Redistributive-and-Regulat ory-Provisions-in-a-Multilevel-Framework.pdf

Schur, L., Kruse, D., \& Blanck, P. (2005). Corporate culture and the employment of persons with disabilities. Behavioral Sciences and the Law, 23(1), 3-20. https://doi.org/10.1002/bsl.624

Shumaker, L. (2015, April 15). Autism and employment: Early leader SAP marches forward. Retrieved from http://blog.sfgate.com/Ishumaker/2015/04/12/aut ism-and-employment-early-leader-sap-marches-for ward

Stewart, D. (2009). Transition to adult services for young people with disabilities: Current evidence to guide future research. Developmental Medicine and Child Neurology, 51(4), 169-173.

The Employment Act of 2004, 435/2004 Coll. Retrieved from https://portal.mpsv.cz/sz/obecne/prav _predpisy/akt_zneni/zoz_od_1-4-2012_en.pdf

The Persons With Disabilities Act of 2006. Retrieved from http://www.ilo.org/dyn/natlex/natlex4.detail?p_lang $=e n \& p \_i s n=88100 \& p \_$country $=U G A \& p \_c o u n t=135 \&$ p_classification $=08.01 \& p \_$classcount $=4$

Trani, J., \& Loeb, M. (2010). Poverty and disability: A vicious circle? Evidence from Afghanistan and Zambia. Journal of International Development, 24(51), S19-S52.

U.N. Division of Social Policy and Development. (2010). Fact sheet: Youth with disabilities. Retrieved from https://social.un.org/youthyear/docs/Fact\%20sheet \%20youth\%20with\%20disabilities.pdf

U.N. Enable. (2017). CRPD and Optional Protocol signatures and ratifications. Retrieved from https://www. un.org/development/desa/disabilities/conventionon-the-rights-of-persons-with-disabilities.html

Unger, D. D., Wehman, P., Yasuda, S., Campbell, L., \& Green, H. (2002). Human resource professionals and the employment of people with disabilities: a business perspective. In D. D. Unger, J. Kregel, P. Wehman, \& V. Brooke (Eds.), Employers' views of workplace supports: Virginia Commonwealth Univer- 
sity Charter Business Roundtable's national study of employers' experiences with workers with disabilities. Richmond, VA: Virginia Commonwealth University.

U.S. Bureau of Labor Statistics. (2016). Occupational employment statistics. Retrieved from https:// www.bls.gov/oes/current/oes_nat.htm\#00-0000

Ventegodt Liisberg, M. (2011). Disability and employment: A contemporary disability human rights approach applied to Danish, Swedish and EU law and policy. Cambridge: Intersentia.

Von Schrader, S., Bruyère, S. M., Malzer, V., \& Erickson, W. A. (2013). Absence and disability management practices for an aging workforce. Ithaca, NY. Retrieved from http://digitalcommons.ilr.cornell. edu/edicollect/1320

Von Schrader, S., \& Nazarov, Z. E. (2016). Trends and patterns in Age Discrimination in Employment Act (ADEA) charges. Research on Aging, 38(5), 580-601. https://doi.org/10.1177/0164027515593989

Vos, T., Barber, R. M., Bell, B., Bertozzi-Villa, A., Biryukov, S., Bolliger, I., . . . Murray, C. J. L. (2015). Global, regional, and national incidence, prevalence, and years lived with disability for 301 acute and chronic diseases and injuries in 188 countries, 1990-2013: A systematic analysis for the Global Burden of Disease
Study 2013. The Lancet, 386(9995), 743-800.

Waddington, L., Pedersen, M., \& Ventegodt Liisberg, M. (2016). Get a job! Active labour market policies and persons with disabilities in Danish and European Union policy. Dublin University Law Journal, 39(1), 1-24.

Waldschmidt, A., Sturm, A., Karačić, A., \& Dins, T. (2017). Implementing the UN CRPD in European countries: A comparative study on the involvement of organizations representing persons with disabilities. In R. Halvorsen, B. Hvinden, J. Bickenbach, D. Ferri, \& A. M. Guillén Rodriguez (Eds.), The changing disability policy system: Active citizenship and disability in Europe. New York: Routledge.

World Health Organization. (2011). World report on disability: Summary, 2011, WHO/NMH/VIP/11.01. Retrieved from http://www.refworld.org/docid/508 54a322.html

Yap, M., \& Konrad, A. M. (2009). Gender and racial differentials in promotions: Is there a sticky floor, a midlevel bottleneck, or a glass ceiling? Industrial Relations, 64(4), 593-619.

Yeo, R., \& Moore, K. (2003). Including disabled people in poverty reduction work: 'Nothing about us, without us.' World Development, 31(3), 571-590.

\section{About the Authors}

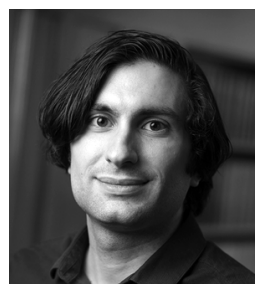

Matthew C. Saleh (PhD, JD) is a Research Associate at Cornell University's K. Lisa Yang and Hock E. Tan Institute on Employment and Disability. He works on a number of projects, including implementation fidelity and collaboration network study for the New York State Promoting the Readiness of Minors in Supplemental Security Income (PROMISE) program. Matt co-teaches the Disability Law course in Cornell University's Industrial and Labor Relations School, and was a 2015-16 U.S. Fulbright Scholar in the Eastern Caribbean.

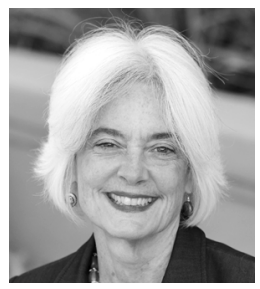

Susanne M. Bruyère (PhD, CRC) is the Director of the K. Lisa Yang and Hock E. Tan Institute on Employment and Disability and a Professor of Disability Studies in the Cornell University ILR School. As Director of the Yang-Tan Institute, she is responsible for the strategic and financial direction of a multi-milliondollar research, training, technical assistance, and information dissemination organization devoted to improving employment outcomes and inclusive communities for people with disabilities. Professor Bruyère is also currently Project Director and a Co-Principal Investigator of research efforts focused on employment disability nondiscrimination and workplace disability inclusion, funded by numerous federal agencies. 